\title{
Revelaciones de la pandemia de COVID-19
}

\author{
Leonardo Viniegra-Velázquez* \\ Unidad de Investigación en Medicina Basada en Evidencias, Hospital Infantil de México Federico Gómez, Ciudad de México, México
}

\section{Resumen}

Bajo la premisa de que «las sociedades revelan sus entrañas en momentos críticos y las ocultan o encubren en situaciones de normalidad», este ensayo emprende, a partir de caracterizar algunas revelaciones de la pandemia de COVID-19 - que ha puesto en jaque al mundo globalizado-, una crítica propositiva de los basamentos de la civilización. En particular, el mito neoliberal como camino único de progreso humano y el del desarrollo tecnológico como esencia del progreso social y razón principal del quehacer científico. Dentro de las revelaciones significativas destaca el desmantelamiento del Estado de bienestar y de los servicios públicos de salud, que hacen vulnerable a la población ante las pandemias; la devastación planetaria, que favorece su emergencia; y la correlación entre el desplome de las actividades humanas y la mejoría (fugaz) de la vida planetaria, que denota la incompatibilidad radical entre la permanencia del capitalismo neoliberal, que todo lo degrada, y la preservación y el cuidado de la vida en su infinita diversidad... jla humana incluida! Se propone otra idea de progreso humano: el auge de los valores implicados en la superación espiritual, intelectual, moral y de convivencia en armonía con el ecosistema planetario. Respecto a las razones profundas de la catástrofe, se argumenta que es la propia humanidad por su forma de ser, de pensar, de actuar, de convivir y de relacionarse con el planeta. Por tanto, la conclusión a la que se llega es la urgente necesidad de emprender un camino alternativo en la búsqueda de otro mundo posible, hospitalario y dignificante para todas las formas de vida.

Palabras clave: Pandemia de COVID-19. Neoliberalismo. Estado de bienestar. Ecocidio. Colapso civilizatorio. Progreso humano.

\section{Revelations from the COVID-19 pandemic}

\begin{abstract}
"Societies unveil their entrails during a crisis and hide or conceal them in normal situations" is the premise of this essay that offers a propositional critique of the foundations of civilization by characterizing some revelations from the COVID-19 pandemic that seriously compromises the globalized world. Especially the neoliberal myth as the only way of human progress, and technological development as the essence of social progress and main reason for scientific research. Among the significant revelations is the dismantling of the Welfare state and public health services, which render the population's vulnerability in the face of pandemics. Planetary devastation favors its emergence, and the correlation between the despondency of human activities and the (fleeting) improvement of planetary life, which denotes the radical incompatibility between the permanence of neoliberal capitalism that degrades everything and preservation and care of life in its infinite diversity, including human life! Another notion of human progress is proposed: the rise of values involved in the coexistence, and the spi-
\end{abstract}

\section{Correspondencia:}

*Leonardo Viniegra-Velázquez

E-mail: leonardo.viniegra@gmail.com
Fecha de recepción: 16-06-2020

Fecha de aceptación: 17-06-2020

DOI: 10.24875/BMHIM.20000160
Disponible en internet: 24-02-2021

Bol Med Hosp Infant Mex. 2021;78(1):75-84

www.bmhim.com

1665-1146/@ 2020 Hospital Infantil de México Federico Gómez. Publicado por Permanyer. Este es un artículo open access bajo la licencia CC BY-NC-ND (http://creativecommons.org/licenses/by-nc-nd/4.0/). 
ritual, intellectual, and moral growth of the human condition in harmony with the planetary ecosystem. Regarding the deep reasons for the catastrophe, it is argued that it is humanity itself by its way of being, thinking, acting, living together and relating to the planet. Therefore, the conclusion reached is the urgent need to undertake an alternative path in the search for another possible world, hospitable and dignifying for all forms of life.

Key words: COVID-19 pandemic. Neoliberalism. Welfare state. Ecocide. Civilizing collapse. Human progress.

«Nuestro mundo, inmerso en una degradación omnímoda, es evidencia del agotamiento y la ruina de una civilización bajo el dominio de los intereses de lucro sin límite, que han convertido en mercancía lo más sublime y vil de la condición humana, y en rentables las peores atrocidades y la devastación planetaria."

El autor

\section{Introducción}

La pandemia de COVID-19, que azota casi simultáneamente a la enorme mayoría de los países del mundo, ha paralizado las actividades económicas, sociales, religiosas, culturales y del mundo del espectáculo deportivo y artístico en una escala nunca vistaa; ha obligado al confinamiento a poco más de la mitad de la población mundial, junos 4000 millones de habitantes!, y por lo mismo, constituye la única calamidad realmente global inédita en nuestra azarosa historia. A estas alturas de su desarrollo (mediados de mayo de 2020), los contagios superan los 4.3 millones y los decesos rondan los 300,000 . Detrás de estas cifras frías y asépticas se esconden incontables tragedias y sufrimientos colectivos, no solo debidos a tantas pérdidas humanas y a circunstancias desgarradoras de la inhumación de multitud de cadáveres, sino también por las inusitadas y restrictivas condiciones de confinamiento, las cuales, con el transcurrir de las semanas y los meses, han tornado agobiante y hasta insoportable la convivencia, propiciando trastornos psicoemocionales, desencuentros, desavenencias y violencia de todo tipo. En medio de tales situaciones límite coexisten infinidad de actos que dignifican la condición humana por su altruismo, generosidad, solidaridad, compasión y empatía, pero también los actos más viles y despreciables, encabezados por empresarios que priman los beneficios sobre la vida de sus trabajadores, exponiéndolos al contagio y eventualmente a la muerte, $u$ otros

a A 2 meses del inicio de la pandemia, las medidas sanitarias de confinamiento empiezan a relajarse paulatinamente en los países que fueron afectados durante la primera etapa. que proceden al despido sin más o se lucran con la tragedia. También destacan algunos gobiernos u organizaciones políticas que priorizan la economía y las ganancias sobre la vida de sus ciudadanos, o que se lucran políticamente con la catástrofe. Aunque se afirma que el virus es "democrático", porque no discrimina por nivel social, esto soslaya que la sociedad sí discrimina de diversos modos y hace más vulnerables a los diferentes, a los «inferiores», a los informales, a los precarizados, a los excluidos y a los migrantes ${ }^{2}$.

Esta sucinta reconstrucción del desarrollo de la pandemia de COVID-19, sesgada de origen ${ }^{b}$, basada en multitud de fuentes periodísticas polarizadas a la cuestión pandémica, en informes oficiales periódicos de la Organización Mundial de la Salud —que por su magnitud, y sobre todo por su vigencia fugaz, es improcedente citar como referencias y en algunos ensayos-, es el punto de partida del presente trabajo, que reflexiona sobre algunas revelaciones de este suceso omnipresente y tan perturbador para la vida humana.

\section{Algunas revelaciones de la pandemia de COVID-19}

La premisa de este trabajo concuerda con lo que varios pensadores han dicho de diversas maneras: «las sociedades revelan sus entrañas en momentos críticos y las ocultan o encubren en situaciones de normalidad». La pandemia de COVID-19, por sus inmensas repercusiones actuales y potenciales, revela con gran poder lo que permanece encubierto o soslayado. A continuación, se presenta un breve recuento de lecciones que ha dejado la pandemia:

1) Aunque la duración de la pandemia, con sus consecuencias y estragos, va para largo y

b No incluye los afanes de miríadas de investigadores por esclarecer las características moleculares del SARS-CoV-2, sus propiedades fisicoquímicas o los mecanismos fisiopatológicos de los daños que provoca, que inundan las publicaciones científicas internacionales en la búsqueda de tratamientos específicos y de vacunas efectivas. Tampoco se detiene en la debacle económica progresiva en curso. 
desconocemos el punto de llegada, los sistemas de salud de los países afectados han sido rebasados, casi sin excepción, en mayor o menor medida, por la abrumadora demanda de atención de afectados por el SARS-CoV-2, provocando en ocasiones sucesos y escenas dantescas que parecen ficción ${ }^{1}$. Al respecto, es obvio que en las condiciones actuales no hay sistema de salud - por preparado que esté ante eventualidades- capaz de contender de manera realmente eficaz la avalancha de casos provocada por una pandemia con diseminación fulminante (en virtud de un mundo hiperconectado por los buenos negocios, no por la cooperación o la solidaridad), que exhibe alarmante contagiosidad y virulencia, y que conforme se prolongan sus cadenas de trasmisión muestra un carácter proteiforme, con crecientes variantes sintomáticas y la afectación de otros órganos, sistemas o aparatos diversos aparte del respiratorio, y una letalidad que parece ir en aumento. He aquí la "carta de presentación» de esta virosis provocada por un agente recién identificado, pero casi por completo desconocido, para la que no se dispone de tratamiento específico de probada efectividad ni mucho menos de una vacuna: un desafío descomunal. No obstante, no deja de sorprender que países que se autocalifican vanguardia de la civilización, como algunos europeos y sobre todo nuestro arrogante y siempre amenazante vecino del norte, hayan gestionado de manera tan negligente y equívoca su propia epidemia, con las consecuencias que están a la vista y que se actualizan día con día, desestimando advertencias de tiempo atrás de sus propios científicos, de las agencias internacionales y de los medios de comunicación acerca de la inminencia de nuevas epidemias $^{1,3}$. Empero, el trasfondo de tan cuestionable gestión de la epidemia no es principalmente la impericia o el desdén gubernamental hacia medidas sanitarias que obstaculicen los grandes negocios, particularmente en los Estados Unidos de Norteamérica', sino el desmantelamiento y la desarticulación - con muchas variantes, grados y matices- de los sistemas de salud pública de la mayoría de los países en aras de una progresiva privatización de los servicios, con el pretexto de elevar la eficiencia y la productividad, que ha adquirido un carácter prácticamente universal en nuestro tiempo ${ }^{4}$. Esta corriente privatizadora irresistible desdibujó instituciones públicas de salud y de seguridad social, desvirtuando su razón de ser: la promoción, el cuidado y la protección de la salud de la sociedad en su conjunto, suplantada progresivamente por una lógica de operación que prioriza altas tasas de ganancia, y donde «la genuina preocupación por la salud de la población» es mera mercadotecnia y simulación.

En nuestro medio, si bien las instituciones públicas de salud aún predominan, el tsunami neoliberal ha significado una merma crónica y progresiva del presupuesto asignado a la salud, adelgazando y precarizando a las instituciones estatales - con excepción de las dependencias dedicadas a los aspectos de promoción, prevención y epidemiológicos, que parecen aprovechar el aprendizaje derivado de contender con el nuevo desafío para operar con efectividad y pertinencia, apelando a la participación social a fin de aminorar los daños de la epidemia y diluirlos en el tiempo-, con el consecuente debilitamiento y las graves limitaciones para enfrentar contingencias de tal magnitud, obligadas a perentorios reajustes de organización, coordinación, ampliación y acción para intentar dar respuesta al momento explosivo del contagio y sus estragos.

Una primera lección de la pandemia de COVID-19 que ha sacudido los basamentos de la civilización y ha expuesto de manera descarnada el debilitamiento suicida de las instituciones de salud estatales es evidenciar la falacia del mito neoliberal como «camino único y horizonte de progreso humano», que ha provocado un desmantelamiento del Estado de bienestar. El neoliberalismo ha desmantelado el Estado de bienestar en beneficio de las grandes corporaciones, y lo ha convertido en mero gestor empresarial -el caso de los Estados Unidos de Norteamérica es emblemático-, con la consecuente imposibilidad para responder apropiadamente al inmenso desafío, en particular con la anticipación, la oportunidad y la efectividad requeridas. A mayor mercantilización del cuidado a la salud que se centra en individuos y no en comunidades, mayor vulnerabilidad de la población ante retos sanitarios de tal envergadura. Tratándose de problemas que se extienden a la sociedad, el fundamento de toda acción realmente efectiva ante tal tipo de desafíos es la respuesta basada en la movilización comunitaria a organizarse, responsabilizarse y actuar para el efecto, confiando en sus autoridades. Los casos de Corea del Sur, Vietnam, Nueva Zelanda e Islandia son ilustrativos ${ }^{1}$.

2) Otra revelación de la pandemia que complementa lo antes mencionado es remarcar lo que es del dominio público: el sector privado no es ni puede ser solución para lograr el cuidado y la preservación efectivos de la salud colectiva, dada su imposibilidad para gestionar una respuesta mínimamente 
coordinada, oportuna y efectiva ante cualquier imprevisto de salud poblacional, máxime ante la que nos azota de una magnitud sin precedentes. Esto es así porque su razón de ser es el lucro, por lo que solo puede beneficiar a clientes pudientes y para problemas individuales no colectivos. De ahí la necesidad urgente de fortalecer las instituciones públicas de salud si aspiramos a un sistema efectivo que permita prever y anticipar contingencias, que es condición para que las acciones sean realmente eficaces al enfrentarlas y, con mayor razón, para cuidar y restablecer la salud de las mayorías depauperadas en tiempos de "calma». No se debe olvidar que está fuera de su alcance contrarrestar los efectos de las desigualdades, como la pobreza y la exclusión que agobian a nuestra población y la hacen vulnerable ante cualquier contingencia sanitaria ${ }^{c}$, porque se trata de graves problemas cuya razón es la imposición del neoliberalismo, que concentró más la riqueza y acrecentó la pobreza.

A modo de corolario de las primeras revelaciones de la pandemia, una precisión obligada y polémica es la siguiente: el «salto" de un virus proveniente de animales salvajes a humanos, sea zoonótico o simbiótico, es prácticamente inevitable en los tiempos actuales ante la devastación de ecosistemas, lo que ha provocado la desaparición de las barreras naturales que existían entre el mundo silvestre y el humano perpetrada por una civilización ecocida (epígrafe). A su vez, esto favorece una frecuencia creciente de esos «saltos", la mayoría sin dejar huella, hasta que algún mutante cambia a una configuración que resulta infectante al interactuar con humanos y da lugar a una nueva virosis. Empero, el que una virosis se convierta en una epidemia, y sobre todo en una pandemia, depende de la forma de ser, de vivir y de relacionarse de las sociedades humanas. Es decir, las formas epidémicas y pandémicas de una enfermedad infecciosa son expresiones socialmente determinadas por el tipo de sociedad que impera en el mundo actual (con muchas excepciones), que además de sobrepobladas son individualistas, competitivas, insolidarias y renuentes a participar en acciones comunitarias y a sentir

c De hecho, el arribo de la COVID-19 es «llover sobre mojado», porque se sobrepone a las «pandemias» de obesidad y diabetes, que también son reveladoras de la falacia del mito neoliberal como única opción de progreso, porque «educó nutricionalmente» a los mexicanos para consumir alimentos procesados y comida chatarra, lo que ahora hace más vulnerable a buena parte de la población a la plaga emergente. responsabilidad o compasión por los otros, lo que favorece la propagación y la transformación de una virosis en epidemia.

3) Una tercera lección de la presencia de la pandemia es que hace evidente, con mayor contundencia, la engañosa idea de progreso grabada a fuego en nuestras mentes, que representa el sostén ideológico de la civilización. Se distinguen dos variantes, una que se refiere al plano nacional-internacional y otra que se refiere al plano social:

a) La idea de progreso imperante en y entre las naciones del mundo es el desarrollo económico que supone un crecimiento incesante (la obsesión por el incremento perpetuo del producto interno bruto), que agota los recursos naturales, genera alta concentración y escasa o nula distribución de la riqueza, desmantela el Estado de bienestar ${ }^{5}$, profundiza las desigualdades y condena a crecientes sectores de la población a la redundancia y la exclusión. ¿Cómo persistir en esta idea de progreso de unos pocos, que requiere para su «buena salud» devastar el planeta, que excluye y desprotege a crecientes sectores de la población y los hace más vulnerables a la mal llamada "contingencia», porque se trata de una "certeza» sobre su inexorable arribo, mas no del momento de su aparición? Otro argumento que desmorona esa idea de progreso lo aporta otra revelación pandémica: la enorme vulnerabilidad de un mundo globalizado por las empresas transnacionales, propias de las economías «fuertes y avanzadas», cuya punta de lanza es la industria armamentista, con sus armas «inteligentes» que se muestran «indefensas» ante la diseminación incontenible de un "cuasi-nano-organismo», que obliga al cierre de millones de empresas, provocando la quiebra o la desaparición de cientos de miles y sumiendo en la orfandad laboral a centenares de millones de trabajadores. A pesar de todo esto, los gobiernos aspiran a regresar a «la normalidad» lo antes posible. Es decir, al imperio de los intereses de lucro sin límite que ha colapsado la civilización 6 .

b) En el plano social se encuentra una añeja idea de progreso que lo equipara con la posesión de riqueza material y que, hoy día, ha alcanzado cotas de concentración escandalosas (la lista de Forbes) a costa del empobrecimiento absoluto o relativo de la inmensa mayoría de la población trabajadora (con una alta vulnerabilidad a la pandemia). Es, pues, una idea insostenible de progreso social. En los tiempos actuales, esa idea ha mutado a la del 
poder adquisitivo, en especial de las últimas tecnologías, precisamente porque la idea de progreso más difundida en la sociedad lo hace depender del desarrollo tecnológico, que puede sintetizarse así: «a mayor desarrollo tecnológico, mayor progreso social; la disponibilidad de tecnología cada vez más avanzada es la palanca fundamental para resolver los mayores problemas que nos aquejan como humanidad $" 7$. Estas ideas absolutamente predominantes que comparte la gran mayoría de la población encuentran un categórico mentís al exhibir, de manera flagrante, que la más moderna y vanguardista tecnología no puede sustituir a las acciones comunitarias bien organizadas y coordinadas con fines anticipatorios, que es lo decisivo para controlar una epidemia (lo que no niega que el buen uso de la tecnología pueda facilitar dichas acciones). La tecnología, ante retos de tal complejidad y magnitud como los que implica una forma pandémica de enfermedad, solo puede representar, en el mejor de los casos, posibilidades para los más afectados por la catástrofe que nos abruma. Es preciso insistir en que las tecnologías entrañan potencialidades, no realidades. La realización de las potencialidades de las tecnologías para la salud depende de sus formas de uso; es decir, los beneficios potenciales se actualizan, bajo formas de uso juiciosas, selectivas, apropiadas, oportunas y pertinentes, a las circunstancias en las que se actúa ${ }^{7}$. Por el contrario, el uso irreflexivo, indiscriminado y rutinario no solo encarece los servicios, sino que puede resultar contraproducente. Se ha designado como tecnofetichismo a esa inclinación generalizada de "deificar la tecnología» al depositar en ella atributos y cualidades sobrehumanas que, por supuesto, no posee, porque todo depende del uso que se haga de ella ${ }^{7}$. A mayor abundamiento, en los países que hasta ahora han logrado gestionar de mejor manera, o menos equívoca, la epidemia, la razón de fondo está relacionada con la participación colectiva, que movilizada bajo formas de organización comunitarias y orientada por objetivos claros logra mayor efectividad en sus propósitos de contención o mitigación de la difusión del virus. He aquí otra lección de la pandemia que amplifica lo obvio: la tecnología es potencialidad, no realidad, y la razón de su desarrollo en el presente no obedece al beneficio colectivo que tanto se pregona, sino al lucro y al control social que requiere la dominación ${ }^{8}$. Es preciso replantear la idea de progreso, no solo en la esfera de la salud, sino en todos los campos de actividad. Debe darse una connotación efectivamente social y humanista referida a ciertos valores - no materiales - que apunten al perfeccionamiento de la vida individual, comunitaria y social, como la que hemos desarrollado en otro lugar9: el auge de los valores implicados en la superación espiritual, intelectual, moral y de convivencia de la condición humana. Esto solo puede tener lugar cuando los ambientes comunitarios se aproximan a sociedades igualitarias, pluralistas, incluyentes, justas, solidarias, cooperativas y en armonía con el ecosistema planetario. Esta idea utópica subraya que el progreso humano no depende de la posesión de bienes materiales, sino de que las personas revaloren y cultiven las diversas esferas de su ser hacia convivencias e interacciones dignificantes, respetuosas, generosas, estimulantes, gratificantes, fructíferas, cooperativas, solidarias y empáticas. En la búsqueda de este progreso como derrotero interminable plagado de obstáculos, las condiciones materiales básicas para vivir con dignidad son un presupuesto necesario para emprender tal camino de superación, mas no parte integrante.

4) Para caracterizar la siguiente revelación de la pandemia de COVID-19 es preciso considerar una de sus mayores consecuencias indirectas: la retracción masiva de la presencia humana de los espacios urbanos y de los acontecimientos sociales, económicos y recreativos, en una especie de autoexilio obligado, cuya prolongación ha tornado agobiante, dolorosa y asfixiante para muchos una convivencia inusitadamente intensa. Pues bien, tal retracción, con el consecuente desplome de la circulación vehicular, del comercio y de la producción industrial, ha representado, de manera paradójica, «una tregua, un respiro, un alivio momentáneo" para el agobiado y degradado ecosistema, al detenerse por un momento el ecocidio perpetrado por una civilización que se autodesigna progresista y avanzada, con la caída súbita, aunque fugaz, de los niveles de contaminación del aire y, en menor medida, de las aguas y de los suelos. Aunado a esto, la casi desaparición de la presencia humana del espacio público ha favorecido el despliegue sin cortapisas de diversas formas de vida y la incursión de muchos integrantes del mundo viviente en el medio urbano. Ambos fenómenos, sugeridos por imágenes satelitales, registros y videos con escenas urbanas que parecen montajes, representan el asomo a un mundo posible, menos inhóspito, con una disminución significativa de la contaminación atmosférica, jen tan 
corto plazo!, y el retorno -efímero- de animales silvestres a sus antiguos dominios, de los que fueron despojados y excluidos por la deforestación, las agroindustrias y las industrias extractivas. Centremos nuestra reflexión en ese efecto indirecto de la pandemia de enormes proporciones con sus dos componentes: de un lado, la sustracción del acontecer social, de actos económicos y sociales de todo tipo a una escala sin precedentes; del otro, indicios inequívocos de una mejoría significativa del ecosistema, en particular en lo que respecta a la atmósfera y al despliegue exploratorio de vida animal. Ambos componentes están asociados estrechamente bajo coordenadas espaciotemporales coincidentes. Es decir, se dispone de registros que sustentan una relación causal del primero sobre el segundo, dada la congruencia temporal de ocurrencia de ambos fenómenos, como para considerarlo un experimento natural único en la historia por su magnitud y globalidad. Como tal, consiste en correlacionar dos variables, con una $n$ prácticamente infinita, que agrupan incontables microsucesos. De ahí que, para los partidarios de los diseños de investigación duros, si son consecuentes, lo observado arroje una sólida evidencia de que a mayor retracción de las actividades humanas, menor daño ambiental y mejores condiciones para el florecimiento de la vida (al respecto, se estima que la disminución sustancial de la contaminación atmosférica ha representado una significativa reducción de la mortalidad de pacientes con neumopatías crónicas). Así, "los resultados del experimento" apoyan de manera contundente (¿confirman?) lo que muchos pensadores críticos han sostenido desde tiempo atrás, y que el poder que sostiene el (des)orden imperante ha desestimado o silenciado: la incompatibilidad radical entre, por un lado, la permanencia del capitalismo en su fase actual, que extrema la explotación del trabajo, ahonda las desigualdades, condena a la exclusión a crecientes sectores de la población, despoja a los pueblos originarios, intensifica el ecocidio, degrada todo lo que toca y aplasta lo que se opone o resiste a la dominación de los intereses de lucro sin límites, y por el otro lado, la preservación y el cuidado de la vida en su infinita diversidad, la humana incluida, condición imprescindible del progreso social entendido como el auge de los valores implicados en la superación espiritual y moral de los humanos, que nos aproxime a formas de vida digna, sobria, estimulante, serena, generosa y fraternal, en armonía con el ecosistema planetario.

\section{Determinantes y significados de la pandemia de COVID-19}

Ahora procede reflexionar sobre algunos determinantes y significados de la irrupción de la pandemia de COVID-19 en el escenario mundial. Para tal propósito, formularemos preguntas que juzgamos obligadas. ¿Por qué y cómo llegamos a esta situación tan perturbadora y dolorosa? ¿Cuáles son las causas? Las respuestas a estas interrogantes no son simples (el virus), sino que entrañan diversos aspectos entrelazados. Así, la presencia de una catástrofe que solo afecta a los humanos, quienes representan una ínfima proporción de la totalidad de los seres vivos pluricelulares y cuya retracción masiva coincide con una mejoría significativa fugaz de la vida planetaria, se explica por razones intrínsecas a los propios humanos y radica en las características de su forma de ser, de pensar, de actuar, de convivir y de relacionarse con el planeta viviente. Antes, un agregado necesario: sin el tipo de educación imperante, encargada de reproducir, generación tras generación, los rasgos sociales predominantes, las características de los humanos actuales no se habrían perpetuado ${ }^{10}$.

a) ¿Cómo somos los humanos de hoy? La forma predominante de existencia de la dignidad humana en el mundo actual es como mercancía intercambiable cada vez más devaluada y desechable. En un mercado de trabajo precarizado, los salarios son raquíticos y los derechos laborales ausentes, y en otros de mayor nivel, cada vez más tecnificados por la informática, la robótica y la inteligencia artificial, la oferta de trabajo se encuentra muy por debajo de la demanda potencial. En ambas situaciones, la población trabajadora depauperada, relegada o excluida del trabajo formal encarna el sector de la economía más vulnerable a la epidemia y contribuye a perpetuarla como víctima propiciatoria de su propagación; al representar la mayor proporción de enfermos afectados, los convierte en focos efectivos de contagio por estar imposibilitados de seguir las recomendaciones sanitarias.

b)A través de las formas de pensar predominantes de las sociedades de nuestro tiempo es cómo el poder y la dominación ejercen un control de las conciencias y de los cuerpos de gran eficacia para perpetuarse; cuanto más imperceptibles sean los dispositivos de control para las víctimas, convencidas de que ejercen "su libertad", mejor control. Esto es así porque en todos los espacios del quehacer social, sin excepción, imperan ciertas ideas y prácticas no por ser 
las mejores o porque hayan mostrado superioridad sobre competidoras o alternativas, sino por su sintonía directa o indirecta con la dominación de los intereses de lucro sin límite ${ }^{11}$. De ahí la invisibilidad para las mayorías instruidas - con niveles de escolaridad sin precedentes históricos- de la degradación extrema y del colapso civilizatorio en el que nos encontramos ${ }^{11}$, suplantado en los medios masivos de desinformación por «una fase dolorosa y pasajera de nuestro camino ascendente de progreso". Estas formas predominantes de pensarnos, a nosotros mismos y al mundo, que interiorizamos por el solo hecho de incorporarnos a determinado espacio de trabajo especializado, operan como soportes o cómplices del capitalismo neoliberal y como lubricante efectivo de su gigantesca maquinaria de destrucción masiva del ecosistema planetario que, como se ha argumentado, favorece la emergencia episódica de virosis de origen animal que se transforman en epidemias y en pandemias.

c) En lo que se refiere a las formas de convivencia prevalecientes, donde el ethos de la civilización está conformado por el individualismo, la pasividad (ante el conocimiento ajeno a la propia especialidad y los excesos del poder), la competitividad, el consumismo y la gran vulnerabilidad a la desinformación (infodemia) son atributos que caracterizan al «individuo normal de la modernidad" (no a las comunidades de los pueblos originarios que resisten la degradación), que suele ser reticente o indiferente a la gestión comunitaria de los problemas sociales y que, particularmente en el caso de la epidemia de COVID-19, suele sabotear las acciones que constituyen la forma más efectiva de detener o lentificar su propagación y atenuar sus estragos. Esos atributos se han designado como degradantes ${ }^{12}$ porque, por un lado, son el soporte social que da viabilidad a un modelo económico y cultural que es incompatible con la preservación y el cuidado de la vida en su conjunto, la humana incluida; por el otro, subyacen a esa apatía, indolencia, indiferencia y permisividad social con la dominación de los intereses de lucro sin límite a escala planetaria, que todo lo degrada, desde la dignidad humana convertida en mercancía desechable hasta la destrucción del ecosistema planetario como empresa muy lucrativa.

d) La forma de relacionarnos con el planeta es, sin duda, el asunto clave para desentrañar la explicación profunda de la emergencia periódica de virosis que toman la forma de epidemias y pandemias; ahora es el turno de la COVID-19. Para entender la peculiar manera antropocéntrica de relacionarnos con la naturaleza es preciso retrotraernos en esta argumentación a los albores de la humanidad, incluyendo el dilatado proceso donde se sucedieron distintas especies del género Homo, que representaron aproximaciones sucesivas hasta culminar (con el Homo sapiens) en un acontecimiento inédito y singular en la historia evolutiva de la vida sobre la Tierra: la conciencia esclarecida del sí mismo en su diferenciación del ambiente exterior amenazante y veleidoso. En otras palabras, hizo su aparición la mirada egocéntrica de la naturaleza, que valora como significativos ciertos objetos circundantes en razón de su utilidad o preferencia para satisfacer las necesidades implicadas en la realización de las funciones vitales básicas: preservación de la integridad y la vitalidad, alimentación, reproducción y convivencia con sus pares, que adquirieron, con el transcurrir del tiempo, complejidades crecientes ${ }^{11}$. La mirada egocéntrica surgió al interior de grupos, donde la conjunción de miradas individuales dio lugar, de manera simultánea, a la mirada etnocéntrica comunitaria respecto a la naturaleza, donde la valoración de los objetos también respondió a la utilidad, pero para el consenso colectivo. Así, el egocentrismo, al subsumirse al etnocentrismo, originó el conflicto existencial fundacional e inextinguible de la condición humana en el plano individual. El etnocentrismo determinó, desde entonces, las formas de interacción de los grupos, tribus o comunidades, y erigió sus mitos fundacionales que confirieron cohesión y sentido a sus miembros. En tiempos mucho más recientes, las razones cohesionadoras se han diversificado: raciales, culturales, religiosas, de origen, de destino, de clase, de casta, de linaje o de sangre; el etnocentrismo es un hilo conductor para entender los abismos de la historia humana, en particular de las guerras perpetuas ${ }^{11}$. Con respecto al antropocentrismo propiamente dicho, punto de llegada del ego y del etnocentrismo que supone a la humanidad en su conjunto, tiene su origen en las religiones monoteístas de la Biblia, que la ubican como centro de todas las cosas y el fin absoluto de la creación. Tal dogma tuvo una vigencia prácticamente universal debido a la imposición del cristianismo durante el prolongado y doloroso colonialismo ${ }^{13}$, en claro contraste con la mirada "antropoexcéntrica» de las religiones politeístas o panteístas «paganas» de los pueblos originarios, colonizados, sojuzgados, diezmados y esclavizados, que reconocían a la Madre Tierra como ente superior, fuente originaria de vida $y$ 
motivo de respeto, cuidado y reverencia ${ }^{14}$. Hoy día, el antropocentrismo se comprende como perspectiva de entendimiento y de interacción con la naturaleza en función de los intereses humanos. Pues bien, ese "antropocentrismo que llevamos dentro" explica la actitud y la práctica generalizadas de apreciar a la naturaleza como fuente inagotable de recursos, como objeto a nuestro servicio o blanco de nuestras inclinaciones a domeñarla o controlarla, y por ende, a destruirla. También, el antropocentrismo, desde sus inicios («la verdad revelada»), incitó la fecundidad de la población que, conforme disminuyó la mortalidad y se censuró el control natal, dio lugar a explosiones demográficas y constituye, hoy día, otra incontenible fuerza devastadora del ecosistema. Hasta hace poco, los ultrajes al ecosistema planetario permanecían silenciosos y apenas suscitaban protestas o movilizaciones fuera de los reflectores, sin encender los focos rojos de los ambientalistas ni las alarmas de los defensores de los pueblos originarios. Con el arribo del neoliberalismo a partir de los años 70 se aceleraron la degradación y la contaminación del aire, de las aguas y de los suelos hasta niveles incompatibles con el florecimiento de la vida; se deforestaron y devastaron amplios territorios, y el calentamiento global, ya irreversible, llegó al primer lugar de la agenda conservacionista. Pese a todas estas atrocidades ambientales que afectan de manera progresiva y negativa a la población humana, las fuerzas destructivas del capital todavía se empeñan en profundizar el ecocidio. Dicho lo anterior, se comprende por qué la visión antropocéntrica del mundo con sus gestantes (las religiones monoteístas), al avalar las formas históricas predadoras de la relación de los humanos con la Madre Tierra, ha operado como patente de corso para que las grandes industrias devasten impunemente nuestra irremplazable casa común, provocando inéditas formas de interacción de $\mathrm{Gaia}^{15}$ con los humanos (expresadas en forma de plagas de todo tipo), que los "antropocéntricos conversos» interpretan como la «venganza de la Tierra» y que ahora se actualiza en forma de pandemia de COVID-19, como en otros momentos ha tomado la forma de huracanes, sequías, inundaciones, incendios o extremos de temperatura de inusitada intensidad. La pandemia revela y nos recuerda que la causa de este y de otro tipo de calamidades - salvo fuertes sismos y tormentas solares de gran magnitud-que afectan gravemente a las poblaciones son los propios humanos: seres portadores de una mirada antropocéntrica de la naturaleza que ha conformado un sistema-mundo que los subordina a la dominación de los intereses de lucro sin límite, que ha devastado la superficie planetaria, degradado la condición humana a niveles y escalas sin precedente, y que ha «dado a luz» seres individualistas, competitivos, consumistas, manipulables e insensibles a la adversidad ajena, que operan como soporte encubridor del colapso civilizatorio en curso. En este hilo argumentativo, la pandemia podría interpretarse, bajo esa lógica destructiva, como "daño colateral» (como muchas otras calamidades), solo que ahora, por la globalidad y la gravedad de los daños, al hacer más ostensible la causa profunda de la pandemia, puede revertirse con más fuerza contra la dominación de los intereses de lucro al intensificarse y escalar las movilizaciones que se oponen.

e) Un breve apunte sobre la educación. La escuela, como depositaria de la reproducción transgeneracional de las relaciones sociales y de los saberes acumulados, desempeña un papel clave en la perpetuación de esas formas de ser, de pensar, de convivir y de relacionarse con la naturaleza. Esto es así porque la forma de educación que impera en la escuela, que denominamos pasiva, obstaculiza la iniciativa del alumnado en la búsqueda y la generación de su conocimiento (opiniones propias sobre los asuntos de su interés), y favorece el consumo indiscriminado y acrítico de la mayor cantidad posible de información, con frecuencia ajena a sus intereses ${ }^{16}$. Se comprende que, en tanto predomine la educación pasiva, la escuela formará seres acomodaticios, sumisos, individualistas, soportes de la degradación y ciegos ante el colapso civilizatorio. Solo la educación inspirada en una crítica implacable y constructiva, cuya pedagogía en un primer momento "contagia entusiasmo» a los alumnos por entender quiénes somos (como humanidad) y dónde estamos (el mundo que habitamos), más allá de las ideas dominantes y, en un segundo, los encauza por el camino interminable de elaboración de su propio conocimiento por medio de la crítica, puede contribuir a la reproducción social de humanos de nuevo tipo y dar surgimiento a otro mundo posible ${ }^{16}$.

\section{Epílogo}

Una aclaración pertinente para los lectores que se atreven a incursionar en el universo de las ideas. Ante la complejidad inherente a los temas tratados en este 
ensayo, ha sido necesario simplificarlo por razones de espacio y, lo más importante, recurrir a ideas, conceptos y teorías de diversas disciplinas en cuyo tratamiento se han difuminado los límites interdisciplinarios, para dar lugar a una aproximación transdisciplinaria al problema tratado, que es nuestra propuesta para aprehender la complejidad (lo que no es garantía de "éxito"). Dicho de otra manera, los argumentos para sustentar las propuestas aquí presentadas no pueden provenir del mundo empírico como «evidencias causales significativas" propias de la causalidad mecanicista que tiene un carácter puntual, simple, inmediato, lineal y unidireccional, ajeno a la complejidad ${ }^{17}$. En sentido inverso, la complejidad teórica desarrollada en este ensayo no es susceptible de confirmación o validación empírica, en ninguno de sus componentes, por la ciencia empirista y reduccionista de vigencia universal. Conceptos y teorías con pretensiones explicativas no pueden ponerse a prueba mediante observaciones y experimentaciones. La forma de desafiarlas, de mostrar sus debilidades, limitaciones o fortalezas es por medio de la confrontación con otras que tengan pretensiones similares, y la decisión se toma con base en el mayor poder esclarecedor de los fenómenos a los que se refieren o el poder explicativo de una mayor diversidad de sucesos implicados en el objeto de conocimiento.

Sirva lo anterior para extraer otra revelación de la pandemia de COVID-19: las graves limitaciones de la ciencia moderna, dominada por el empirismo reduccionista $^{18,19}$ (con aversión a las ideas explicativas y comprensivas), para esclarecer fenómenos complejos -inherentes al proceso vital- como la pandemia. Tales limitaciones revelan, a su vez, que el empirismo reduccionista no predomina por una supuesta superioridad sobre otros enfoques epistemológicos, sino porque sus resultados (matematizados) son fuente primaria de la innovación tecnológica en la lucha encarnizada de las corporaciones por el control del mercado y unas altas tasas de ganancia. El empirismo reduccionista es la versión del quehacer científico que guarda mayor sintonía con los intereses de lucro sin límite ${ }^{8}$. Al respecto, la ciencia actual altamente especializada ha sido configurada por la lógica del capitalismo y responde de manera obligada al criterio de rentabilidad en dos direcciones: al consumir equipos y reactivos onerosos o al patentar descubrimientos. Esto explica la absoluta prioridad de la investigación del micro-cosmos y el nano-cosmos en la esfera de la salud, porque es capitalizable en innovaciones tecnológicas; por contraste, las ideas explicativas son inútiles 0 , peor aún, obstáculos para los buenos negocios ${ }^{8}$.

Una ciencia depauperada de ideas comprensivas y explicativas está condenada a la irrelevancia intelectiva de la complejidad (inherente a los fenómenos vitales). Si bien la ciencia actual es imprescindible en el desarrollo tecnológico, al obedecer a los dictados de la gigantesca maquinaria destructiva neoliberal, dista de encarnar la quintaesencia del progreso. Más bien, su papel en muchos casos es apuntalar los mecanismos de dominación y control social con sus aportes tecnológicos: militares, espaciales, informáticos, plataformas de internet, de la salud o dispositivos «inteligentes» ${ }^{8}$, cuyas formas de uso refuerzan y perpetúan la dominación de los intereses que han colapsado la civilización. De ahí, su carencia de legitimidad para arrogarse el monopolio del conocimiento verdadero, válido y confiable, y de excluir, por «no científicos», saberes teóricos o empíricos valiosos que no cumplen con sus criterios de cientificidad.

Para concluir, considerando lo argumentado anteriormente, puede afirmarse que la pandemia de COVID-19 es la expresión más reciente, más dramática y de mayor envergadura de la extrema degradación en que nos encontramos. Es un clamoroso llamado a la urgencia de encauzar nuestro devenir hacia un derrotero de progreso genuino de la condición humana, que supone reconocer y ubicar, como dos fundamentos de todo movimiento social encaminado en la búsqueda efectiva de otro mundo posible, de un lado el respeto, el aseguramiento y la progresión de los derechos humanos, sobre todo en su connotación comunitaria y con carácter universal, y de otro lado, la revaloración, el cuidado y la preservación de la diversidad biológica de los ecosistemas. Ambos son, a nuestro entender, las únicas garantías de una permanencia humana digna y constructiva en el atribulado, despiadado y devastado mundo que nos toca vivir.

\section{Responsabilidades éticas}

Protección de personas y animales. Los autores declaran que para esta investigación no se han realizado experimentos en seres humanos ni en animales.

Confidencialidad de los datos. Los autores declaran que han seguido los protocolos de su centro de trabajo sobre la publicación de datos de pacientes.

Derecho a la privacidad y consentimiento informado. Los autores han obtenido el consentimiento informado de los pacientes o sujetos referidos en el 
artículo. Este documento obra en poder del autor de correspondencia.

\section{Conflicto de intereses}

El autor declara no tener ningún conflicto de intereses.

\section{Financiamiento}

Ninguno.

\section{Bibliografía}

1. Ramonet I. La pandemia y el sistema-mundo. La Jornada en Línea, 25 de abril 2020

2. Santos BS. La cruel pedagogía del virus. Buenos Aires: CLACSO; 2020

3. Davis M. El año de la peste. La Jornada en Línea, 9 de abril 2020.

4. Navarro V. Ataque a la democracia y al bienestar. Crítica al pensamiento económico dominante. Barcelona: Anagrama; 2015. p. 61-73.

5. Navarro V. Las consecuencias del neoliberalismo. Ataque a la democracia y al bienestar. Crítica al pensamiento económico dominante. Barcelona: Anagrama; 2015. p. 114-54.
6. Viniegra-Velázquez L. Educación y proyecto vital en un mundo en colapso civilizatorio. Parte I. Inv Ed Med. 2016;5:199-209.

7. Viniegra-Velázquez L. El fetichismo de la tecnología. Rev Invest Clin. 2000;52:569-80.

8. Viniegra-Velázquez L. El reduccionismo científico y el control de las conciencias. Parte II. Bol Med Hosp Infant Mex. 2014;71:323-8.

9. Viniegra-Velázquez L. El bien vivir: ¿cuidado de la salud o proyecto vital? Parte II. Bol Med Hosp Infant Mex. 2016;73:283-90.

10. Viniegra-Velázquez L. El paradigma pasivo en la educación. La educación y la crítica del conocimiento. Una perspectiva transdisciplinaria para entender la subjetividad y sus posibilidades cognitivas. México: Invipress-Hospital Infantil de México; 2015. p. 69-79.

11. Viniegra-Velázquez L. El orden cultural, la enfermedad y el cuidado de la salud. Bol Med Hosp Infant Mex. 2017;74:397-406.

12. Viniegra-Velázquez L. La crítica y la educación médica: hacia un conocimiento liberador. Parte I. Bol Med Hosp Infant Mex. 2018;75:327-37.

13. Santos BS, Meneses MP. Introducción. En: Santos BS, Meneses, MP, editores. Epistemologías del sur (perspectivas). Madrid: Akal; 2014. p. 8.

14. Santos BS. Más allá del pensamiento abismal: de las líneas globales a una ecología de saberes. En: Santos BS, Meneses, MP, editores. Epistemologías del sur (perspectivas). Madrid: Akal; 2014. p. 48.

15. Lovelock J. Las edades de Gaia. Una biografía de nuestro planeta vivo. Barcelona: Tusquets; 2000

16. Viniegra-Velázquez L. Hacia un nuevo paradigma de la educación. Rev Invest Clin. 2008;60:337-55.

17. Viniegra-Velázquez L. Crítica de la causalidad mecanicista en las ciencias de la vida. Bol Med Hosp Infant Mex. 2019;76:155-66.

18. Honderich T, editor. Empiricism. The Oxford Companion of Philosophy. New York: Oxford University Press; 2005. p. 242-5.

19. Honderich T, editor. Reductionism. The Oxford Companion of Philosophy. New York: Oxford University Press; 2005. p.793-5. 